"This is an Accepted Manuscript of an article published by Taylor \& Francis in Culture and Organization on 15/04/14, available online: http:// wwww.tandfonline.com/10.1080/14759551.2014.901324 ."

\title{
Ambicultural blending between Eastern and Western paradigms: Fresh perspectives for international management research
}

\author{
Dr. Sid Lowe \\ University of Wollongong in Dubai \\ Faculty of Business and Management \\ Blocks 5, 14 \& 15, Dubai Knowledge Village \\ P.O. Box 20183 \\ Dubai, U.A.E \\ Tel) +97143672400, \\ Fax) +97143672760 \\ E-mail: drsidlowe@yahoo.co.uk
}

\section{Dr. Astrid Kainzbauer}

College of Management

Mahidol University

69 Vipawadee Rangsit Road

10400 Bangkok, Thailand

Tel.: +66-2 2062000 - ext 2032

Fax: +66-2 2062000 - ext 2090

E-mail: cmastrid@mahidol.ac.th

\section{Dr. Nirundon Tapachai}

Kasetsart University

Faculty of Business Administration

50 Paholyothin Rd. Jatujak

Bangkok 10900

Thailand

Tel.: + 6629428691

Fax: + 6629428693

E-mail: ntapachai@yahoo.com

\section{Dr. Ki-Soon Hwang*}

Kingston Business School

Kingston University

Kingston Hill

Kingston-Upon-Thames

Surrey KT2 7LB, UK

Tel: +44 (0)208 4175652

Fax: +44 (0)208 4175026

Email: k.hwang@kingston.ac.uk

\section{* Corresponding Author}




\title{
Ambicultural blending between Eastern and Western paradigms: Fresh perspectives for international management research
}

\begin{abstract}
East and Southeast Asian worldviews are distinctly different from those of the West. Westerners and Asians construct their environment differently not least because they construct the notion of 'self' very differently. This paper describes and exemplifies distinctions in cognitive and linguistic styles between East and West and outlines the implications of these styles for environmental perspectives and research paradigms. Examples from Thailand illustrate the philosophical roots and practical implications of an indigenous Eastern perspective for local business interactions. We explore out the privilege afforded in Western, Cartesian paradigms in (Asian) management research and stimulate debate on the benefits of promoting alternative Asian indigenous perspectives for both management research and management practice. We support the idea that Asian management discourse needs more self-confidence and deserves a more prominent place in international research, not least because international management research will greatly benefit from freshly 'blended' perspectives that incorporate Eastern and Western perspectives.
\end{abstract}

Keywords 'East', 'West', Language, Thought, Ecologies, Thailand

\section{Introduction}

We begin by discussing the problems of Western ethnocentrism in Asian Business research. We then compare the different cultural systems in the East and West through different cognitive and linguistic styles. We certainly recognize the limitations of conceptualising 'national' cultures and that neither the 'East' nor the 'West' is homogenous or unchanging (McSweeney 2009). However, we nevertheless feel confident in making some assertions about broad differences in cognition, language and environmental perspective between 'imagined communities', such as nations, that can be subsequently subjected to empirical investigation. Nisbett's (2003) notion of cultural differences in habits of thought and linguistic styles is a useful one. These habits and styles are subject to fluctuation, improvisation, change and experimentation. As a result, describing differences between East and West in these terms involves describing differences in process. Different processes are not different 'things' but different narratives for constructing identities and 'making sense' of the world. If, in describing differences between East and West, we were claiming to describe different 'things' then our comparisons would be somewhat ridiculous. What we are trying to describe, however, are broadly different styles of imagination which allow people to enact different worlds through culturally-specific social practices.

The paper will explore the differences in Western and Eastern ways of thinking based on philosophical roots and subsequently provide Asian indigenous examples mostly from a Thai business perspective. Our intention is to advocate an 'ambicultural' approach to international management research which benefits from integrating some Eastern indigenous perspectives with some Western viewpoints.

\section{Western ethnocentrism in Asian business research}


It has been recognized that there is an asymmetry in transnational encounters in management and business (Westwood 2001). This is particularly evident with the research in Asian Business and Management. Trying to understand Eastern phenomena through a Western 'lens' may lead to Western bias and consequent misinterpretations due to underlying differences in worldviews. A Western scientific mindset is underpinned by a 'modernist', rationalistic worldview. Following on from an ancient Greek approach and contemporary Cartesian thought, research of business and management has developed various models and theories to rationalize the phenomena of business and management. For a long period scientism or universal rationalism has been the single correct, objective mode of representing immanent or metaphysical 'truth'. A rich, eclectic qualitative research legacy has, until very recently, been progressively marginalized in International Business research by disciplinebased theories and quantitative, positivistic empirical methodologies (Birkinshaw, Brannen, and Tung 2011), resulting in advances in abstract generalizations but blindness towards contextual, indigenous understanding. A Western rationalistic research lens applied to Asian management research implements the application of Cartesian binary logic. This kind of dualism usually involves a 'black and white' logic, which applies its bivalent (either-or) ideology universally and without reflection to 'fuzzy' or paradoxical issues. Cartesian logic involves reducing phenomena to dualistic or bivalent categories, one of which is designated as 'subject' and the other is denigrated as 'object'. However, during turbulent and increasingly uncertain times, Western rationales have difficulties in dealing with contemporary complex and paradoxical issues. Many assume that in a more chaotic era, more than ever, managing a successful business requires taking higher risks, applying more creative thinking, and responding more quickly to everyday crises. Some management writers increasingly recognize the need to appreciate culturally-bound phenomena through more of an indigenous mindset (Bhagat, McDevitt, and McDevitt 2010; Chen and Godkin 2001; Chen 2002; Chen, Chen, and Xin 2004; Lee and Ellis 2000; Leung 2006; Redding 1993; Tung 1994; Wah 2001; Yeung and Tung 1996; Tsui 2004). Li (2012) outlines indigenous research as polyvalent and argues for a 'geocentric' approach integrating Western and Eastern approaches. Primecz, Romani \& Sackman (2009) identify 'multiple culture perspectives' as a relatively more recent alternative to the dominant 'cross-national comparison' perspective of the national cultural model and the emergent anthropological/interprevist inspired challenger, which they term 'intercultural interactions' Similarly, Lowe (2003) argues that the Western paradigms have dominated the study on Chinese culture and management for long enough. This leads to the claim that 'Managing in Changing Times' (Lowe 2010) requires a move away from reliance upon scientific rationalism and its colonizing universalism. We argue here that because of the hegemony of Western theory, the integrative 'geocentric' ambitions of $\mathrm{Li}$ (2012) could too easily ignore the incommensurabilities between Western structuralist/etic and Eastern process/emic 'paradigms'. In order to explore this claim and to move toward resolution of the problem we need to clarify the differences between East and West that make some Western approaches increasingly questionable in Eastern contexts. Our purpose is to argue for a move towards blending theories in context, according to situated problems and sensitive to what will work best according to local conditions.

\section{The geography of thought}

Nisbett (2003) characterises differences between 'Asian' and 'Western' cognition in terms of Eastern 'circularity' and Western 'linearity'. In terms of philosophical consequences, this draws upon assumptions of processual holism, complexity and contextual thinking in the East by contrast to objective categorization, rule-based rationalism and deterministic thinking in the West. According to Bedi (1999), Eastern holism cultivates an expectation of treating the 
lives of people as wholes and with traditional personalistic humanism. Asian management's "cultural nuances are more finely tuned than the quantitative approach practised by many Western professional managers. It puts a premium on human relations and on social values" (Bedi 1999, 4).

The Greek philosophy that frames contemporary, modernist Western thought as exemplified by Aristotle, Plato and Parmenides is characterised by a search for causality, an existential assumption of a static underlying reality and a dedication to model the real external environment through objective scientific techniques, democratic debate and individual identity. Aristotle's' phronesis, the process view of Heraclitis and other Greek philosophies of 'metos' (navigations between polyvalent subjective-contextual understandings, oscillation between chaos and cosmos) were to be discarded in the 'modernist' Cartesian era which produced universal objective representation as the only feasible episteme (Cummings and Wilson 2003, p.9). The modern, Western 'representational subject' that constitutes Descartes' cogito had, according to Deleuze (1968/1994), its antecedence in Aristotle and its continuance with Kant. By contrast to the Cartesian subject, pre-modern understanding was dominated by 'emic', analogical, embodied and experiential knowledge favouring orientation and action. The modernist episteme privileges a more 'etic' understanding, involving logical and reasoned orientation over embodied experience/ analogical reasoning and imposing top down direction over bottom up emergence and context-dependent action. Mechanistic, modernist reality solely as an omnipotent, objectively seen representation of 'cosmos' is conceived as an arrangement of identifiable objective elements, each with its own discoverable properties and moving according to discoverable laws (Shotter 2008).

By contrast Chinese philosophy, as an example of Eastern episteme, is more usually characterised by 'connectionism' and 'field dependence' that is more akin to ancient Greek notions of 'metos' and a lot closer to contemporary Western 'post-structuralist' (particularly Deleuzian) notions of 'immanence' and de-centring of the subject. The collective Chinese identity is accomplished through Confucian 'harmony'. This worldview is characterized by change, contradiction, paradox and uncertainty (Chen 2002). An Eastern holistic understanding requires comprehension of the complexity of contexts. Mainstream (CartesianNewtonian) Western philosophy on the other hand is a lens that prefers certainty and determinism over uncertainty, paradox and relativism, and objectivism over subjectivism. The preference for certainty and objectivism produces unwitting Western ethnocentrism in an Eastern lifeworld where the wisdom of uncertainty and paradoxical subjectivity are normative. For example Eastern Taoist / Buddhist reality is not amenable to categorization and establishment of deterministic laws. The Chinese Taoist dialectic is opposite to Western Cartesian logic and rejects the simplification of categorization and rule formation in favour of a holistic and contingent view of reality. The Eastern tolerance for contradiction is rooted in Eastern philosophy and religion. Reality is seen as dynamic and due to constant change, so that all so-called 'things' are related and interdependent (Samson 2004). The Eastern 'environment' is, therefore, not the same 'thing' as in the West. In fact the Western concept that the environment is a thing does not apply in Asia. The Eastern view is that 'it' is a holistic and contextual 'field of forces' whose reality is contingent upon complex interconnections that resist simple categorization and explanation through rules or laws. It is a complex process not reducible to separate categories, such as political, economic, social and technological differences commonly constructed in the West. 


\section{Different types of 'self'}

\section{The Western mindset: I think therefore I am}

The Cartesian, Western self exists as an individual because (s)he can, above all, think. Identity is associated therefore with the knowledge which sustains it. The knowledge sought of the Western self answers the question 'Who am I?' The Western normative assumption is that knowledge, constituted through abstract representational language, should precede action. This "knowledge-creation-application-performance" style (Chia 2003, 953) develops a philosophical stance derived from selective interpretations of Aristotle, predominant adoption of Platonic essentialism and 'modernist', Cartesian-Newtonian philosophy generally.

The lasting legacy of Aristotle, under the yolk of a dominant Cartesian episteme of modernism, has not been his understanding of practical wisdom and subjectivity but his assumption of causality and the search for a correspondence of truth which is embedded in modern Western languages. Truth is expressed as a noun rather than an adjective, as an unquestioned object with empirical evidence. Truth, within this worldview of Western Enlightenment philosophy, is 'found' rather than made (or socially constructed). It is found through rationalism and is assumed to be universal. The Western mind has inherited the 'structural representationalism' of Aristotle and of Descartes' Cogito. Descartes sought an absolute, certain knowledge. The Western, cognitive self is therefore a construction that invents its existence through separation and the certainties provided by rational knowledge and knowledge awareness.

\section{The Eastern mindset: I am not separate}

Chinese philosophy differs from Western thought in content and methodology (van Norden 1996, 225) and in its greater emphasis upon humanism, synchronicity and balance. Similarly, Chinese ethical thinking emphasizes a complex interrelationship between moral virtue and duty (Hansen 1996). The Eastern self is, by contrast with the Western individual and cognitive self, contingent upon affective relationships with much less emphasis upon the individual. Asian children are not raised for independence but to serve the conventions of filial piety and family commitment. The Asian self and Asian identity is collective and may be regarded as a 'familial self' (Roland 1988), embedded in a web of close emotional relationships. Words for self are also various in East Asian languages and depend upon which self is engaged in co-operative interaction (Nisbett 2003, 158). In the Thai language for example, there are up to 17 different forms of ' $\mathrm{I}$ ' and up to 19 different forms of 'you' to choose from. A speaker of Thai language must demonstrate relational flexibility as well as sensitivity in choosing the right form of address for a particular context (Chantornvong 1992). An error may cause offence. As a result, as with most East Asian cultures, the Thai view of 'self' entails an understanding of identity as a relative and contingent process embedded in the context of interaction with others. The ideal Buddhist Thai self can be interpreted as somewhat opposite to the Western self, given that the objective of Buddhist enlightenment is to ultimately transcend a self (and all its concomitant 'delusions') completely.

In Eastern cultures, fatalism towards the environment is normative. The collective identity provided by family, clan and nation provides courage to face the joys and sufferings of life together with significant others. Most Eastern philosophy emphasizes the notion of karma 
(from Sanskrit meaning 'action') and teaches us to focus on virtuous action (Siddiqui 2005, 13) and ethically positive 'processes' (Kaizen in Japanese). The results will consequently, it is assumed, take care of themselves. Such fatalistic thinking sensitises the Eastern actor to uncontrollable nature. In other words, Man does not control nature; he must work with, through and because of it.

Chinese philosophy has always emphasized change over permanence. In Eastern cultures "despite their apparent cultural diversities and ideological differences, the invisible, the tacit, the spoken and the implied are inevitably preferred over the visible, the explicit, the written and the articulate" (Chia 2003, 957). Buddhist scholars, for example, traditionally make use of symbols and metaphor in their teaching in order to encourage intuitive, embodied understanding. Students are expected to elaborate on the hints from the master in order to construct the whole picture (Wozniak 2006). Eastern 'Knowledge' is consequently only transmitted through a trusting relationship. For example, Thai relationship orientation is evident in teacher-student relationships. Students must respect their teacher and in return, teachers are expected to take care of students. Consequently, it is not uncommon in Thailand that a teacher's role goes much beyond the narrow definition of providing classroom instruction and includes personal care and attention for a range of topics outside the classroom. Teachers may be seen as guardians, role-models, foster-parents, etc. This personalistic bond is developed through a virtue practice called 'Wai Kru' ceremony. Wai kru is a Thai ritual in which students pay respect to their teachers in order to express their gratitude. Annually held in schools and universities in Thailand it forms the basis of the Thai student-teacher relationship. Apfelthaler et al. (2005) showed that Thai students tend to think that their professors are more responsible for their success/failure than they are themselves. Failing an exam or a class may be attributed to lack of preparation and guidance from the professor. From a Thai perspective, both professor and student share the responsibility for success or failure of the student.

Buddhism in particular seeks Enlightenment for all living beings. All objects and experiences are products of the mind and so are mentally constructed rather than discovered. The Lord Buddha is attributed as saying that 'with our thoughts we make the world'. This notion is reflected in the Thai parable of a young, Western-educated Thai man who became a monk in a remote Thai temple. Unhappy with the ascetic conditions and the austere situation, he complained to the Abbot who in return told him the story of a dog suffering from leprosy. Trying to relieve the itching feeling which it thought was created by the floor, the dog constantly moved around to find the place where the itching would cease. The story suggests that this metaphor helped the young monk to become aware that his unhappiness came from within himself. Buddhists believe that reality and the self are made by the mind and Man has a spiritual agency in that his deeds will either improve or detract from Karma. Karma is a Sanskrit word which means intentional 'action' and it "denotes an active force, the inference being that the outcome of future events can be influenced by our actions" (Tenzin Gyatso 1999, 141). In Buddhism, Enlightenment can only be achieved through dedicated meditation and by practicing virtuous action and so cannot be 'taught' in a conventional Western manner. In Buddhist meditative practice, the objective is to cultivate a 'communion with the present' where reality is beyond words or belief and disconnected from the past or the future. The Lord Buddha requires you to "Don't just do something, stand there" (Siddiqui 2005, 59). Living the moment requires the giving up of self to focus upon the happiness of others, and arriving at the juncture where mind (thought) and body (experience) are synonymous.

\section{Different discourses}


In Western thought, representations of reality are embedded in modern, low-context Western languages which cultivate categorical binary oppositions, with little or no emphasis upon 'fuzzy' shades of grey or paradoxes. Objective descriptions are embedded in language and language constitutes what counts as knowledge. Western languages are focused upon attributes of objects (adjectives) and the transformation into abstract categorization through use of nouns. Adjectives in English, for example, can be granted noun status by adding "ness" as a suffix (Nisbett 2003, 9). For example, white becomes 'whiteness' and kind becomes 'kindness'. Language in Western cultures 'reports' on a real world, discovering its reality through abstraction, categorization and establishing rules or laws to comprehend it. In the Aristotelean West, language is crucially important for establishing the logic of the "knowledge-creation-application-performance" sequence (Chia 2003, 953) because the knowledgeable person must first have a command of rhetoric to be effective and convincing. In Western cultures, knowing is a prerequisite of action and knowing is accomplished through language. To act rationally requires you to know what you are doing and to know what you are doing requires you to be able to communicate before doing it.

High-context Eastern languages, by contrast, are not afforded the same status, function or role as in the West. Within Taoism, the ultimate 'sublime' reality can only be experienced not spoken of, explained or analyzed. The Tao is eternal transformation that cannot be represented by language except as metaphor in relational context (Chia 2003, 958). This encompasses notions of the flowing course of nature and the universe's simultaneous patterns of order and chaos, which can only be experienced intimately through virtuous practice. In Chinese culture, engagement with change and transformation engenders a preference for correlative rather than linear causal thinking (Chia 2003, 963).

Eastern languages are more phonetic and contextual than Indo-European languages. In 'topicprominent' Eastern languages words are more polysemic and the context of the sentence indicates meaning (Nisbett 2003, 157). In such languages, the subject is not the focus. The emphasis is on the context instead. Typically an East Asian language would require one to say 'this place, walking is good' rather than 'walking in this place is good'. In East Asian languages verbs rather than nouns are important (Nisbett 2003, 149) and communication is oriented to relationships rather than abstract objects. Concrete bodily sensual impressions are preferred to abstractions in Eastern languages. So, for example, in Thai language, a diabetic articulates his or her condition as Baa-waan or 'sweet pee'; an embodied metaphor expressing an abstract condition through a corporeal experience. Another example is when going to a meeting where criticism is expected, Thais often use the embodied metaphor Hong Yen which translates as 'cold room'. In the non-Cartesian Thai lifeworld embodied tropes are pervasive. Speaking of the world is to create it and this is reflected in the organization of Eastern languages. Chinese languages, for example, are ideographic, which serves to promote communication, information and knowledge (or 'discourse') that is contextual and tacit. Tropes and idioms are used more frequently than abstract categorization. Chinese 'Mandarin', for example, has developed as 'non-alphabetic' through use of ideogrammatic characters. As a consequence it tends to avoid the preoccupation with literal meaning characterized in 'alphabetic-literate' cultures (Chia 2003, 957). In reflection of this, Chinese language is not a receptacle of Truth but a vehicle for communicating social virtues and is regarded by speakers as an inappropriate vehicle for communicating or understanding spiritual virtues. Language for the Chinese is not the vehicle for communication of wisdoms, which cannot be spoken. One can learn about eternal truth but such understanding cannot be expressed in language (Siddiqui 2005, 25) or grasped by a logical mind (Siddiqui 2005, 29). 
Chinese is, therefore, a multi-valued language that appreciates paradoxical or 'fuzzy', "intervening shades of grey between the extremes of black and white" (Emmet 1991, 45).

The Eastern archetype has been described as favoring 'aesthetic' rather than scientific constructions (Lessem and Palsule 1997, 48) and does not seek an absolute Truth. An aesthetic construction is oriented towards 'Virtue'. This means that action is not determined by the rationalist identification of what is 'True' and proven but by a nominalist consensus about what is acceptable and what 'we', together, can work with. The wisdom of virtuous leadership is in the humanistic capacity to harmonize the imagination of the family, group, clan or nation. When discourse (language, communication. power/knowledge) becomes a focus and as metaphors and other tropes, narratives and stories become central issues, the indeterminacy and unpredictability (Gabriel, Geiger, and Letiche 2011; Riad 2011) that ensues requires incorporation of this indigenous episteme. The powerful Western mythologies of scientism, often expressed through figurative language, that valorize 'rigorous' plots of superior, logico-scientific, rational and objective pictures of reality can no longer go unchallenged (Caicedo 2011).

\section{Different environmental lenses}

Differences in cognition, identity and discourse between 'East' and 'West' lead to our proposition that the 'environment' is not the same phenomena in each culture. In the West, the environment is a consequence of objectification and categorization by scientific analysts who have classified their selves as 'internal' and the environment as 'external. The discourse in the West about increasingly turbulent environments is, in the East, often met with a polite or silent response which we can translate as 'and so what? What's new?' The relationshiporiented cultures of East Asia have always considered 'environments' as complex, immanent and mysterious. The Eastern response has always been to improve the quality of relationships to enable practical, virtuous, collectively consensual, pragmatic, co-operative 'surfing' of turbulence and uncertainty. This is unlikely to change because it appears to be a more successful way to deal with contemporary turbulent complexity than the 'paralysis of analysis' engendered by Western rationalist logic and objective scientific environmental classification. More likely, Eastern leaders and organizations will intensify their efforts to enhance the quality and effectiveness of their relationships and continue to benefit from what has worked well for them in the past into the foreseeable future while at the same time integrating those Western practices which are deemed practically useful.

The integration of different perspectives is an inherent part of Eastern holistic thinking and examples for such a "best of both worlds" approach can be observed in Asian management practice. For example, Chen and Miller (2010) demonstrate important and effective 'ambicultural' practices. International management research would equally benefit from such an ambicultural approach with its inherent openness towards new synthesized or blended ways of thinking.

\section{Business perspectives from Thailand}

A contextual analysis of Thai business practices and underlying values provides insights into the emic complexity of an Eastern worldview. Thai leadership, communication, motivation, conflict management, decision processes and power processes are specific to the highly personalistic-affective, relational, Buddhist value system in Thailand. Over-reliance on the etic values model of Hofstede (1980) has in the past denigrated the significance of local 
emics, such as the Buddhist influence in Thailand. "Besides Hofstede's culture theory, it is always said that to truly understand the Thai culture, one must be familiar with the essence of Thai Buddhism consisting mainly of the four sublime states of consciousness and the four noble truths" (Niffenegger, Kulviwat, and Engchanil 2006, 407). In Thailand, business and Buddhism are complementary. A current example of the perceived benefits of combining Buddhism and business is demonstrated by Thai $\mathrm{Ha}$, a diversified packaged-rice company. Their CEO, a Thai MBA graduate from the US, believes in blending a Western scientific systematic business approach with Buddhist values (The Nation Newspaper 2008, 10a):

\begin{abstract}
"Before holding any major business meeting, Thai Ha staff are encouraged to watch a video of a monk who preaches Buddhist principles. The CEO of Thai Ha says Dhamma can complement business conduct by helping one wash out the "dirt" in one's mind, relieving anger and through these efforts, gain wisdom".
\end{abstract}

This Thai CEO applies what Chen and Miller (2010) call an 'ambicultural' approach to management by blending best practices of both East and West. Western managers in Thailand can find themselves confronted with unusual Thai business methods. A good example is the experience of a Spanish manager in Thailand, who tried to push the sales team for new strategies to overcome a sales decline due to the economic crisis. Instead of reflecting on sales methods, the team suggested to bring in nine Buddhist monks (nine is an auspicious number in Thailand) to bless the products and pray for more sales success in an elaborate Buddhist ceremony. What seems strange and even ridiculous to Western managers carried a deep spiritual meaning for the Thai sales staff and the gained spiritual strength boosted their morale to improved sales efforts. The example shows the disparity between the Western rationalist logic with its notion of separation of business and spirituality and the Eastern notion of interconnectedness of all life spheres.

In terms of leadership, the most important virtue of the Thai manager is to accumulate Baramee; mutual respect, love and loyalty from followers (Komin 1999). The accumulation of a reputation for moral goodness, selflessness and kindness that elicits admiration, honour and respect requires a culturally accomplished communication style. Such a style is likely to be a consequence of blending between Western and Thai ecologies, particularly in the context of an overseas MNC with a relatively young, westernised workforce. Indeed Parboteeah, Paik and Cullen (2009) report a positive correlation between Buddhist values and extrinsic (material) and instrinsic (prosocial) work values. Thai employees prefer consultative managers in preference to autocrats, even if their preferences do not match their perceptions and experiences (Yucongdi 2010). Thai discourse must "be 'polite' and 'considerate', with or without an authoritative overtone" (Komin 1999, 269) so the leader with Baramee is both benevolently paternalistic and authoritatively competent. Although Baramee is partly developed through competence, managerial skills and personal status (both acquired and ascribed), a leader with Baramee must also be moral, ethical and able to win the heart (Krong Jai) of his/her subordinates guided by Buddhist Dharma. Dharma is composed of giving (Dana), morality or virtue (Sila), and mental culture or meditation (Bhavana) with the latter being the most important. Moral discipline, therefore, is central to leaders earning the respect of their subordinates and contributes to the development of Baramee. In their study on leadership in Thai community organizations, Kemavuthanon and Duberley (2009) highlight the important impact of Buddhism on the construction of leadership in Thailand. They identify the four sublime Buddhist attitudes as part of the personal qualities expected of a leader; goodwill (Metta), compassion (Karuna), appreciative gladness (Mudita) and equanimity (Upekkha). Leadership in Thailand requires a holistic perspective; it concerns life both inside and outside of the organization and extends to the families of employees as well 
as to the local community. These authors emphasize that local leadership concepts are culturally constructed and understanding leadership in Thailand requires an understanding and application of Buddhism.

The affective and emotional priority of Thai culture emphasizes the 'heart' over the rational 'head'. Just as there are allegedly more than a hundred words for snow in Eskimo and Inuit languages, there are ubiquitous references to the 'heart' in Thai discourse. For example, 'Khow jai' is often taken as 'to understand' but literally means to 'enter the heart'. In the Thai psyche comprehension and understanding is not just cognitive but also emotional and embodied. In Thai culture the emotional value of interpersonal relationships is particularly emphasized. The dedication towards reciprocity of kindness is expressed in the term Bunkhun (indebted goodness), which often used for the face to face relationship between two people doing favours for each other out of gratitude. Far beyond a mere transactional reciprocation of favours, Bunkhun is based on giving kindness without expecting anything in return, and gratitude. This creates the basis of a deep, meaningful and lasting relationship (Komin 1991). Thus a Bunkhun relationship develops when a person feels grateful to others who render Bunkhun (e.g. goodness, help, etc.) and acknowledges kindness (Roo Jak Bunkhun) as well as reciprocal kindness whenever possible (Tob Thaen Bunkhun). A Bunkhun relationship may be abused when trying to 'create gratitude' (Saang Bunkhun) by rendering help to others with an expectation to get something in return. Such 'selfish' behavior is considered inappropriate among Thais. Even though the Bunkhun concept may seem idealistic from a (Western) rational perspective, it can be explained with the Thai fundamental value of "Nam jai" (literally 'water of the heart') requiring flowing kindness, generosity and empathy without expecting anything in return. The main relational focus is, therefore, on unreserved helping each other (Chuay lue gun).

An example of this was when a British manager of an international hotel group in Thailand recounted a lesson learned from one of her Thai employees on the Thai notion of Bunkhun. Her Thai director of sales was shocked when he learned that she intended to pressure one of their biggest Thai clients for payment according to international head office standards and procedures. The alternative Thai solution for this situation included a personal conversation with the client and an offer to be flexible with corporate rules. This solution helped to 'save face' on both sides and the client, grateful for the flexibility and the special treatment he had received, not only paid swiftly but also returned his obligation by showing loyalty and subsequently brought in even more business. Western 'heartless' objectivity applied to this Thai business context could have meant sacrificing a long-term business relationship for a short-term gain. A similar orientation was identified in Patterson and Smith's (2001) study on relationship benefits in service industries. Thai consumers were found to be loyal to serviceproviders because of a perceived Bunkhun relationship which guarantees them special treatment if needed. The authors also found it interesting to note that the perceived relationship benefits had the highest weight for Thai consumers and the lowest weight for US consumers. The strong Thai emphasis on personal relationships is also confirmed by Srijumpa, Speece, and Paul (2002), who show that lack of human interaction leads to dissatisfaction of Thai customers using internet self-service offered by Thai stockbrokerage firms.

The problems caused by different discourses are somewhat under researched in Eastern and Asian Management studies. One exception is the ethnography of a Thai subsidiary of a Western chemical company conducted by Boode (2005). This study shows how a largely ethnocentric approach, even if moderated by some concessions to local culture, silenced local 
expression through the imposition of English as the lingua franca and demonstrated problems of a low-context, 'open communication' style that violated Thai kreng jai (good hearted feeling considerate for another person, not wanting to impose or cause another person trouble). Kreng Jai cultivates a propensity of conflict avoidance or "potentially traumatic or discomforting situations" (Andrews and Chompusri 2001, 87). In Boode's (2005) case the imposition of Western management discourses (that offended local sensibilities or which were differently interpreted locally) met with quiet, non-compliant indigenous resistance and unspoken dissatisfaction from Thai employees. Western rationalistic managerial logic can seem offensive and 'heartless' to Thai sensibilities. More often they can be seen as unsophisticated. The English language cannot carry the sentiments and tacit expectations of Thai culture and its imposition is an unwitting denigration of these indigenous values. Language and discourse in a Thai business context therefore can be an implicit source of power and hidden conflict between foreign 'culture of the head' and indigenous 'culture of the heart'.

Applying a Western "modern" lens to interpret Thai business relationships often leads to misinterpretations, underestimates traditional practices and neglects established local wisdom - as demonstrated by Thompson (1989) in his study on cross-cultural management of labour in Thailand. The apparent 'lack of Western modern union laws' and 'unavoidable exploitation of labour' as diagnosed from a foreign research perspective is not perceived as such by local Thais. Thai labour management is handled with interpersonal subtlety and finesse rather than reliance on external laws and regulations. The Eastern emphasis on harmony and subtle balance replaces the Western projection of an inevitable antagonism between employers and workers. The Western emphasis on formalistic procedures and legal rights is substituted with a Thai informal dialogical ideal (Thompson 1989). Relying on a philosophical tradition which favours holistic understanding over analytic cognition, Thai managers pay greater attention to personal relationships and subtle changes in their social environment. Decisions are formed intuitively and often embrace a long-term, inclusive and balanced perspective designed to respect the dignity of all parties.

\section{Summary and conclusions}

Our paper explores the implications of Nisbett's (2003) The Geography of Thought proposing how different ecologies in the East and West foster different philosophical, cognitive and linguistic styles and different political, economic, social and technological conditions. In doing so, we have examined how linguistic and philosophical lenses and not merely cognitive approaches are useful for the ambition of developing a holistic indigenous approach to Asian management (Sinha, Kao, and Wilpert 1999). We should recognise that we and Nisbett (2003) somewhat present the distinction between 'East' and 'West' in rather Cartesian dualistic terms and, given more space, would argue in favour of rather less in black and white antinomies. In other words, notions of 'East' and 'West' are grossly oversimplified dualisms. They are not homogenously distinct entities as, for example, Thai culture and Chinese culture have many similarities but very many differences too. However, given that Western academies are expressly or tacitly subject to the influences of Cartesian thought, we anticipate that reflections about the nuances of differences between East and West and indeed within those two cultural spheres probably has to start with our inherited biases and dualistic stereotyping. Our main point is that the failure of Euro-American ethnocentric approaches to deal with contemporary complex indigenous issues makes it all the more imperative to seek alternatives to dominant 'global' business models. The current global economic crisis, among other things, requires Asian management researchers and managers to reflect carefully on the 
values which motivate indigenous business endeavours and to refocus on sustainability and people-orientation over rapid, value-free growth. Indigenous discourses, philosophies and practices not only deserve a more prominent place in international research but Asian research, as such, needs more self-confidence (Fang 2010; Meyer 2006) in employing indigenous rather than Western philosophies in its attempt to explore local wisdom. These indigenous understandings seem to have greater connection to ancient Greek approaches to the 'metos' of subjective polyvalence, which accepted paradox as normal.

One obvious example of the limitations of modern Cartesian dualistic theorising to understand Asian reality are Hofstede's cultural dimensions. According to Hofstede (2001), China is high on collectivism and long-term orientation. However in China today, opposite value orientations such as individualism and short-term orientation are equally prevalent and coexist with the traditional value orientations. While this contradiction might be confusing from a Western bipolar "either-or" perspective, it is perfectly acceptable from an Asian "both-and" perspective which embraces paradox and change (Fang 2010; Fang and Faure 2011). An example of a cultural paradox from the Japanese business context shows that even though Japanese Uncertainty Avoidance (UAI) is classified as very high and American UAI as rather low, Japanese tend to prefer flexible contracts while Americans prefer comprehensive contracts that foresee all contingencies. This paradox can partly be explained with the Japanese reliance on personal relationships and the American reliance on the legal system to resolve disputes. Osland and Bird (2000) use this example to point out the limitations of simplified bipolar dimensions and to emphasize the importance of understanding the local sensemaking context.

Fang (2010) has eloquently examined some of the important implications of Eastern dialectical (Yin / Yang) thinking and calls for 'self' confidence to move on from Hofstede's (1980, 1991, 2001) 'paradigmatic' variance modelling of mental programmes. Our view is that this needs to be taken further into discursive, institutional and action 'programmes'. Indigenous 'self-confidence' certainly requires a move far beyond Hofstede's (2007) Asian viewpoint but additionally requires a move away from the dominance of cognition, psychology and the 'Cartesian self' and towards indigenously relevant, embodied mindsets. Amongst other things, this calls for a much greater emphasis upon indigenous 'discourse' (knowledge, language and communication), indigenous institutional formation and indigenous practices and action.

In our example of Thai business world, we have shown the particular importance of Buddhism on discourse, institutions, cognition and action. Buddhism in Thailand promotes the adoption of a holistic perspective and not only a focus on material development but also on the development of moral and spiritual aspects (inner power, living in harmony with the environment). Thai progress does not always mean looking West and adopting Western models. Progress may well be identified in local ways of managing in order to re-establish indigenous Thai-self confidence and Thai-self respect in research and practice.

Emancipation from the largely predominant notion of Western supremacy in research and management requires a new recognition of the value of local Asian solutions not only for local Asian contexts but also even for Western and global contexts. Western managers and researchers may receive valuable inspiration for dealing with the ever increasing complexity of global political, economic and social environments from the Asian embodied, holistic, intuitive way of thinking (Kainzbauer 2010) because a holistic, intuitive awareness of dynamic realities seems to have distinctive advantages in dealing with complex situations 
(Dijksterhuis 2004, Patton 2003). Eastern paradoxical dualism has already begun to be explored in strategy (Mintzberg 2001; Chen 2002), communication theory (Cheng 1987; Yuan 1997) and knowledge management (Chae and Bloodgood 2006). This is complementary to an increasing interest in management studies of promoting 'wisdom' (Weick 2001) and the importance of complexity and Post-Cartesian, paradoxical approaches (Cameron and Quinn 1988; Clegg, Cunha, and Cunha 2002; Denison, Hoojiberg, and Quinn 1995; Eisenhardt 2000; Lewis 2000; Van de Ven and Poole 1988).

The implications of our paper are that differences between the Western and Eastern lifeworlds are far more extensive and complex than can be captured by attention to cognition and 'values' alone. The differences involve constructions of self, identity and institutions (particularly the family), discourses, the 'environment' and cognitive styles. What is more, these differences are inter-related and involve diverse imaginative and paradoxical processes that cannot be measured by single instruments and methods or explored by isolated paradigms. Western methods and theories for exploring Asian management can contribute to the subject but not without the urgent development of complementary indigenous perspectives. In our view, this means an immediate future characterised not by the geocentrism advocated by Li (2012) but a kind of plurivocal or 'polyphonic' (Bakhtin 1984) multiplicity of independent and unmerged 'voices' that can, nevertheless, be blended through dialogical imagination (Bakhtin 1981) in situ to understand and resolve local problems. Asian management research can strengthen its theory building by combining 'lenses' (Okhuysen and Bonardi 2011) and blending both Eastern and Western perspectives. But, in our view, this does not necessitate a 'geocentric' paradigm. A rebalancing away from Western scientism with its emphasis upon cognition and toward Eastern paradoxical holism is imperative, in our view, for (Asian) management research and practice.

The motivation for a more practical orientation is to cultivate a more paradigmatically integrative research 'relevance' (Corley and Gioia 2011) that Asian actors might actually be able to use and Asian researchers can use sympathetically within indigenous Asian contexts. To have any effect and make any real difference it will need to pass the test of blended theories which should "have explanatory power and are able to energize coherent and sustainable programs of research" (Cornelissen and Durand 2012, 154). Blending or "conceptual blending" (Fauconnier and Turner 2002) is an approach that Oswick, Fleming and Hanlon (2011) have recommended as a solution to the problem of overreliance upon oneway borrowing from outside organization theory and other management disciplines. Blending is a means by which management disciplines, using an approach based upon analogical reasoning, can develop more original 'indigenous' theories in order to cultivate more relevant and appropriate theories and to reduce the reliance on borrowed and 'shipped in' theories from outside. In studies of culture and organization, Lowe, Carr and Moore (2007) have suggested three degrees of blending, namely 'paradigm sliding', 'paradigm crossing' and 'paradigm transcendence'. Paradigm sliding involves attempted integration of contributions that exist within the same paradigm to create new knowledge. The example given is an opportunity for 'sliding' between the approaches of Schwartz $(1992,1994)$ and Strauss and Quinn (1997). Paradigm crossing is a strategy outlined by Shultz and Hatch (1996). Paradigm crossing involves recognising and engaging multiple paradigms requiring the cognitive flexibility to accept the coexistence of multiple truths and the expectation of benefits of mutual arising from the synthesis of apparent opposites. Lewis and Grimes (1999) suggest that a multiple paradigm approach reveals a greater understanding of complexity enabling the abandoning of a 'realist', correspondence conception of truth evident with paradigmatic parochialism. Paradigm transcendence is the most ambitious form of blending and involves a 
conscious attempt to transcend the potentially debilitating 'incommensurability' debate in management disciplines by effectively dismissal of paradigms. In sympathy with this form of 'radical' blending, a suggestion has been made to promote a bricolaged approach (Alasuutari $1995,2)$ that accepts that there is no final understanding, model or knowledge form that corresponds to a totalising truth. A good example, in the field of strategy, of blending that transcends cultural and philosophical roots is that of Nonaka and Zhu (2012). They draw on the pragmatism to be found in America (Peirce, James and Dewey), Europe (Aristotle's notion of phronesis or practical wisdom, Foucault and Habermas) and, particularly, the Far East (Confucius). This kind of blending gains from its abandonment of location in any particular tradition, bounded by tacit cultural assumptions about the world and, by incorporating as equally valuable an 'Eastern' tradition, avoids Western worldview biases. 


\section{REFERENCES}

Alasuutari, P. 1995. Researching culture: Qualitative method and cultural studies. $2^{\text {nd }}$ ed. London: Sage.

Andrews, T., and N. Chompusri. 2001. Lessons in 'cross-vergence': Restructuring the Thai subsidiary corporation. Journal of International Business Studies 32, no. 1: 77-94.

Apfelthaler, G., K. Hansen, S. Keuchel, M. Neubauer, S.H. Ong, N. Tapachai, and C. Mueller. 2005. Cross-cultural learning styles in higher education. International Journal of Learning 12, no. 5: 247-56.

Bakhtin, M.M. 1981. The dialogic imagination: Four essays (trans. C. Emerson and M. Holquist). Austin: University of Texas Press.

Bakhtin, M.M. 1984. Problems of Dostoevsky's poetics (trans. C. Emerson). Minneapolis University of Minnesota Press.

Bedi, H. 1999. Understanding the Asian manager. Sydney, Australia: Allen and Unwin.

Bhagat, R.S., A.S. McDevitt, and I. McDevitt. 2010. On improving the robustness of Asian management theories: Theoretical anchors in the era of globalization. Asia Pacific Journal of Management 27: 179-92.

Birkinshaw, J., M-Y. Brannen, and R.L. Tung. 2011. From a distance and generalizable to up close and grounded: Reclaiming a place for qualitative methods in international business research. Journal of International Business Studies 42: 573-81.

Boode, G. 2005. Boundaries on the move: The impact of cultural values on organizational design and communication within an organization within Thailand. Asia Pacific Business Review 11, no. 4: 519-33.

Caicedo, M.H. 2011. The story of us: On the nexus between metaphor and story in writing of scientific articles. Culture and Organization 17, no. 5: 403-16.

Cameron, K.S., and R.E. Quinn. 1988. Organizational paradox and transformation. In Paradox and transformation: Toward a theory of change in organization and management, ed. R.E. Quinn and K.S. Cameron, 1-14. Cambridge, MA: Ballinger Publishing Co.

Chae, B., and J.M. Bloodgood. 2006. The paradoxes of knowledge management: An Eastern philosophical perspective. Information and Organization 16: 1-26.

Chantornvong, S. 1992. To address the dust of the dust under the soles of the royal feet: A reflection on the political dimension of the Thai court language. Asian Review 6: 14463.

Chen, M.J. 2002. Transcending paradox: The Chinese middle way perspective. Asia Pacific Journal of Management 19: 179-99. 
Chen, C.C., Y.R. Chen, and K. Xin. 2004. Guanxi practices and trust in management: A procedural justice perspective. Organization Science 15, no. 2: 200-9.

Chen, C., and L. Godkin. 2001. Mianzi, guanxi and Western prospects in China. International Journal of Management 18, no. 2: 139-47.

Chen, M.J., and D. Miller. 2010. West meets East: Towards an ambicultural approach to management. Academy of Management Perspectives 24, no. 4: 17-24.

Cheng, C. 1987. Chinese philosophy and contemporary human communication theory. In Communication theory: Eastern and western perspectives, ed. D. Lawrence, 23-40. San Diego: Academic Press.

Chia, R. 2003. From knowledge-creation to the perfecting of action: Tao, Basho and pure experience as the ultimate ground of knowing. Human Relations 56, no. 8: 953-81.

Clegg, S.R., J. Cunha, and M. Cunha. 2002. Management paradoxes: A relational view. Human Relations 55, no. 5: 483-503.

Corley, K.G., and D.A. Gioia. 2011. Building theory about theory building: What constitutes a theoretical contribution? Academy of Management Review 36, no. 1: 12-32.

Cornelissen, J.P., and R. Durand. 2012. More than just novelty: Conceptual blending and causality. Academy of Management Review 37, no. 1: 152-4.

Cummings, S. and D. Wilson. (2003). Images of strategy. Ch 1 in Cummings, S and D. Wilson (Eds.) Images of Strategy. Oxford,U.K.: Blackwell.

Deleuze, G. (1968/1994), Différence et repetition (Paris,1968). Difference and Repetition trans. Paul Patton (1994: Colombia University Press, New York).

Denison, D.R., R. Hooijberg, and R.E. Quinn. 1995. Paradox and performance: Toward a theory of behavioral complexity in managerial leadership. Organization Science 6: no. 5: 524-40.

Dijksterhuis, A. 2004. Think different: The merits of unconscious thought in preference development and decision making. Journal of Personality and Social Psychology 87: 586-98.

Eisenhardt, K. 2000. Paradox, spirals, ambivalence: The new language of change and pluralism. Academy of Management Review 25, no. 4: 703-5.

Emmett, E. 1991. Learning to philosophise. Harmonsworth, U.K.: Penguin.

Fang, T. 2010. Asian management research needs more self-confidence: Reflection on Hofstede (2007) and beyond. Asia Pacific Journal of Management 27: 155-70.

Fang T., and G.O. Faure. 2011. Chinese communication characteristics: A Yin Yang perspective. International Journal of Intercultural Relations 35: 320-33. 
Fauconnier, G., and M. Turner. 2002. The way we think: Conceptual blending and the mind's hidden complexities. New York: Basic Books.

Gabriel, Y., D. Geiger, and H. Letiche. 2011. The marriage of story and metaphor. Culture and Organization 17, no. 5: 367-71.

Hansen, C. 1996. Duty and virtue. In Chinese language, thought and culture: Nivison and his critics, ed. P.J. Ivanhoe, 173-92. Chicago and La Salle, Ill: Open Court.

Hofstede, G. 1980. Culture's consequences: International differences in work-related values. Beverly Hills, CA: Sage.

Hofstede, G. 1991. Cultures and organizations: Software of the mind. London: McGraw-Hill.

Hofstede, G. 2001. Culture's consequences: Comparing values, behaviors, institutions, and organizations across nations. $2^{\text {nd }}$ ed. Thousand Oaks, CA: Sage.

Hofstede, G. 2007. Asian management in the 21st century. Asia Pacific Journal of Management 24: 411-20.

Kainzbauer, A. 2010. Perplexity in Southeast Asia: De-perplexing the expat. In Managing in changing times: A guide for the perplexed manager, ed. S. Lowe, 345-64. Sage, India: Response Books.

Kemavuthanon, S., and J. Duberley. 2009. A Buddhist view of leadership: The case of the OTOP project. Leadership and Organization Development Journal 30, no. 8: 737-58.

Komin, S. 1991. Psychology of the Thai people. $2^{\text {nd }}$ ed. National Institute of Development Administration (NIDA), Bangkok, Thailand.

Komin, S. 1999. The Thai concept of effective leadership. In Management and cultural values: the indigenization of organizations in Asia, ed. H.S.R. Kao, D. Sinha and B. Wilpert, 265-86. New Delhi, Thousand Oaks, London: Sage.

Lee, M.Y., and P. Ellis. 2000. Insider-outsider perspectives of Guanxi. Business Horizons 43, no. 1: $25-30$.

Lessem, R., and S. Palsule. 1997. Managing in four worlds: From competition to co-creation. Oxford: Blackwell.

Leung, K. 2006. The rise of East Asia: Implications for research on cultural variations and globalization. Journal of International Management 12: 235-41.

Lewis, M.W., and A.J. Grimes. 1999. Metatriangulation: Building theory from multiple paradigms. Academy of Management Review 24: 672-90.

Lewis, M.W. 2000. Exploring paradox: Toward a more comprehensive guide. Academy of Management Review 25, no. 4: 760-76. 
Li, P.P. 2012. Toward an integrative framework of indigenous research: The geocentric implications of Yin-Yang Balance. Asia Pacific Journal of Management 29, no. 4: 849-72.

Lowe, S. 2003. Chinese culture and management theory. In Chinese culture, organizational behavior, and international business management, ed. I. Alon, 3-26. Santa Barbara, CA: Greenwood Publishers.

Lowe, S. ed. 2010. Managing in changing times: A guide for the perplexed manager. Sage, India: Response Books.

Lowe, S., A. Carr, and F. Moore. 2007. Paradigmapping studies of culture and organization. International Journal of Cross Cultural Management 7, no. 2: 237-50.

Maruyama, M. 2004. Polyocular vision or subunderstanding. Organization Studies 25, no. 3: 467-80.

McSweeney, B. 2009. Dynamic diversity: Variety and variation within countries. Organization Studies 30, no. 9: 933-57.

Meyer, K.E. 2006. Asian management research needs more self-confidence. Asia Pacific Journal of Management 23: 119-37.

Mintzberg, H. 2001. The Yin and the Yang of managing. Organizational Dynamics 29, no. 4: 306-12.

The Nation Newspaper. 2008. Firm takes principled path to success. The Nation Newspaper, 17 October: 10a.

Niffenegger, P., S. Kulviwat, and N. Engchanil. 2006. Conflicting cultural imperatives in modern Thailand: Global perspective. Asia Pacific Business Review 12, no. 4: 403-20.

Nisbett, R.E. 2003. The geography of thought. London: Nicholas Brealey Publishing.

Nonaka I., and Z. Zhu. 2012. Pragmatic strategy: Eastern wisdom, global success. Cambridge: Cambridge University Press.

Okhuysen, G., and J.-P. Bonardi. 2011. Editor's comments: The challenges of building theory by combining lenses. Academy of Management Review 36, no. 1: 6-11.

Osland J.S., and A. Bird. 2000. Beyond sophisticated stereotyping: Cultural sensemaking in context. The Academy of Management Executive 14, no. 1: 65-77.

Oswick, C., P. Fleming, and G. Hanlon. 2011. From borrowing to blending: Rethinking the process of organizational theory building. Academy of Management Review 36, no. 2: 318-37.

Parboteeah, K.P., Y. Paik, and J.B. Cullen. 2009. Religious groups and work values: A focus on Buddhism, Christianity, Hinduism and Islam. International Journal of Cross Cultural Management 9, no. 1: 51-67. 
Patterson, P.G., and T. Smith. 2001. Relationship benefits in service industries: A replication in a Southeast Asian context. Journal of Services Marketing 15, no. 6: 425-43.

Patton, J. 2003. Intuition in decisions. Management Decision 41, no. 10: 989-96.

Primecz, H., Romani, L. and Sackmann, S. 2009. Multiple perspectives in cross-cultural management', International Journal of Cross Cultural Management 9(3): 267-74.

Redding, G. 1993. The spirit of Chinese capitalism. Berlin: De Gruyter.

Riad, S. 2011. Terms of engagement: On the differential effects of metaphoric utterances in relational stories of organization. Culture and Organization 17, no. 5: 373-88.

Roland, A. 1988. In search of self in India and Japan: Toward a cross-cultural psychology. Princeton: Princeton University Press.

Samson, A. 2004. Contradictions in counter-intuitive beliefs and naïve dialecticism. Journal of Cognition and Culture 4, no. 2: 373-90.

Schultz, M., and M.J. Hatch. 1996. Living with multiple paradigms: The case of paradigm interplay in organizational culture studies. Academy of Management Review 21: 52957.

Schwartz, S.H. 1992. Universals in the content and structure of values: Theoretical advances and empirical tests in 20 countries. In Advances in experimental social psychology, ed. M. Zanna, Vol. 25, 1-65. New York: Academic Press.

Schwartz, S.H. 1994. Beyond individualism/collectivism: New cultural dimensions of values. In Individualism and collectivism: Theory, method, and applications, ed. U. Kim et al., 85-119. Sage.

Shotter, J. 2008. Dialogism and polyphony in organizing theorizing in organization studies. Action guiding anticipations and the continuous creation of novelty. Organization Studies. April, Vol.29. No.4: 501-524.

Siddiqui, M. 2005. Corporate soul: The monk within the manager. London: Sage.

Sinha, D., H.S.R. Kao, and B. Wilpert. 1999. Introduction: the emergence of indigenization. In Management and cultural values: the indigenization of organizations in Asia, ed. H.S.R. Kao, D. Sinha and B. Wilpert, 19-26. New Delhi, Thousand Oaks, London: Sage.

Srijumpa, R., M. Speece, and H. Paul. 2002. Satisfaction drivers for internet service technology among stock brokerage customers in Thailand. Journal of Financial Services Marketing 6, no. 3: 240-53.

Strauss, C., and N. Quinn. 1997. A cognitive theory of cultural meaning. Cambridge: Cambridge University Press. 
Tenzin Gyatso (His Holiness the Dalai Lama). 1999. Ancient wisdom, modern world: Ethics for the new millennium. London: Abacus.

Thompson, A. 1989. Cross-cultural management of labour in a Thai environment. Asia Pacific Journal of Management 6, no. 2: 323-38.

Tsui, A.S. 2004. Contributing to global management knowledge: A case for high quality indigenous research. Asia Pacific Journal of Management 21, no. 4: 491-513.

Tung, R.L. 1994. Strategic management thought in East Asia. Organisational Dynamics 22, no 4: 55-65.

Van de Ven, A., and M.S. Poole. 1988. Paradoxical requirements for a theory of change. In Paradox and transformation: toward a theory of change in organization and management, ed. R.E. Quinn and K.S. Cameron, 19-64. Cambridge, MA.

van Norden, B.W. 1996. What should Western philosophy learn from Chinese philosophy. In Chinese language, thought and culture: Nivison and his critics, ed. P.J. Ivanhoe, 2249. Chicago and La Salle, Ill.: Open Court.

Wah, S. 2001. Chinese cultural values and their implication to Chinese management. Singapore Management Review 23, no. 2: 75-84.

Weick, K. 2001. The attitude of wisdom: Ambivalence as the optimal compromise. In Making sense of the organization, ed. K. Weick, 361-79. Cambridge: MA, Blackwell Publishing Ltd.

Westwood, R. 2001. Appropriating the other in the discourses of comparative management. In The language of organizations, ed. S. Linstead and R. Westwood, 241-82. London: Sage.

Wozniak, A. 2006. Managerial intuition across cultures: Beyond a "West-East Dichotomy". Education and Training 48, no. 2/3: 84-96.

Yeung, I.Y.M., and R.L. Tung. 1996. Achieving business success in Confucian societies: The importance of Guanxi (connections). Organisational Dynamics 25, no. 2: 54-66.

Yuan, R. 1997. Yin/Yang principle and the relevance of externalism and paralogic rhetoric to intercultural communication. Journal of Business and Technical Communication 11, no. 3: 297-320.

Yucongdi, V. 2010. A study of Thai employees' preferred leadership style. Asia Pacific Business Review 16, no. 1-2: 161-81. 